\title{
LA CONSTITUCIÓN \\ DE UN ESTAMENTO EN LA ALEMANIA \\ DE ENTREGUERRAS: ESTUDIO \\ SOBRE LA BIOGRAFÍA DEL CONDE \\ STAUFFENBERG $(1907-1944)^{1}$
}

Pilar Bardo Torres

\begin{abstract}
RESUMEN
La legitimidad del estamento aristocrático que casi monopolizaba el alto funcionariado alemán entre 1871 y 1918 se constituía en la celebración ritual de la violencia y la muerte en la guerra. Por obra del ritual, el lenguaje político del Antiguo Régimen adquiría una significación abstracta que daba sentido a la muerte del individuo. En la biografía del conde Stauffenberg, los conceptos políticos desbordan la esfera propiamente política y constituyen a la muerte como "horizonte de sentido" profundamente enraizado en la personalidad. La crisis biográfica sufrida por Stauffenberg y también por otros nobles alemanes tras la derrota en la primera guerra mundial pone de manifiesto que la legitimidad política no se encontraba entonces diferenciada en términos propiamente políticos, sino incorporada en un estamento aristocrático.
\end{abstract}

\section{LA DIFERENCIACIÓN ENTRE ESTADO Y SOCIEDAD}

La biografía del conde Stauffenberg y sus dos hermanos escrita por Peter Hoffmann (Hoffmann, 1992) ha permitido, por la exhaustiva documentación que contiene, relacionar en el estudio que sigue un proceso de psicosociología histórica como es la incorporación de la legitimidad política en la personali-

${ }^{1}$ Este estudio no hubiera sido posible sin la ayuda prestada por la biblioteca del Instituto Goethe de Madrid.

\section{Reis}


dad, y un proceso histórico de larga duración que es la constitución del Estado alemán. La abundancia de documentación en torno a la figura de Stauffenberg, oficial de caballería nacido en 1907, se debe a que el 20 de julio de 1944 encabezó un golpe de Estado cuyo detonante era un atentado contra Hitler. El círculo Kreiseuer, donde se gestó el golpe de Estado, estaba compuesto por políticos, altos funcionarios y militares, gran parte de los cuales eran de origen noble (Van Roon, 1967). También sobre ellos hay bibliografía, pero la fuente mejor documentada que se ha encontrado es la biografía del conde Stauffenberg. En algunas de las biografías estudiadas hay referencias dispersas a una crisis biográfica que habría tenido lugar tras la derrota en la primera guerra mundial y la desaparición del imperio y del estamento político que cuasimonopolizaba el alto funcionariado alemán (Van Roon, 1967: 6-209). Durante los años de entreguerras y hasta 1944, los nobles alemanes se esforzaron por recobrar la cohesión y la legitimidad social y política de su estamento, a la cual iba indisolublemente ligada su identidad. La legitimidad política se encontraba incorporada en la familia real y en el estamento aristocrático. De ahí que su desaparición diera con frecuencia lugar a una crisis biográfica. El golpe de Estado de 1944 supone el último de los esfuerzos de la aristocracia por reconstruir un estamento indisolublemente político y social.

La diferenciación de la legitimidad política ha sido conceptualizada por la sociología histórica anglosajona como separación entre Estado y sociedad civil (Pérez Díaz, 1993: 95-96). De acuerdo con el paradigma mencionado, que conserva un componente normativo, la diferenciación entre Estado y sociedad civil puede situarse históricamente en la emergencia de las monarquías absolutas. El desarrollo de la economía capitalista fue precedido por el absolutismo: «(...) En el feudalismo, la autoridad política se encuentra demasiado parcelizada y mezclada con la propiedad de la tierra como para dejar a la sociedad civil funcionar en forma de mercado (...). Concentrando y destilando la soberanía política en sí mismo, el estado absolutista despolitizó la sociedad civil de una forma apropiada para el desarrollo de las relaciones de mercado" (Crouch, 1986: 180-181).

La obra de Norbert Elias ha sido fundamental en el estudio histórico contenido en los apartados II y III (Elias, 1989 y 1990). Pero los problemas analíticos surgidos en el curso de la interpretación de los textos históricos ha puesto de manifiesto que la especificidad del contexto histórico en que se gestó El proceso civilizatorio, la sociedad centrada en el Estado que era Alemania antes de 1945, ha dado lugar a un problema de tipo ideológico, que puede hacer necesaria una reconstrucción, en el sentido de introducir un supuesto de diferenciación entre estado y sociedad. La obra de Norbert Elias centra la evolución social en la construcción de los Estados, a partir del surgimiento de las primeras monarquías absolutas en el siglo XV. Desde la sociología histórica anglosajona se ha señalado que las teorías de la evolución social reproducen ideológicamente el centramiento en el Estado de las sociedades en que surgieron, en la medida en que el sistema político se considera como el principal factor inte- 
grador. Charles Tilly ha puesto en duda toda la visión evolutiva de la historia como moldeada por procesos concomitantes de diferenciación e integración, y de los desequilibrios entre ambos como fuente de conflicto anómico (Tilly, 1991: 17). En estos términos, las teorías de la evolución social pueden considerarse como ideologías codificadas en el siglo XIX por intelectuales de la Europa continental que se debían al mecenazgo del Estado (Pérez Díaz, 1993: 9293). Élites culturales aliadas con la "nobleza de toga» que ocupara el alto funcionariado se habrían encontrado desbordadas por las rápidas transformaciones del capitalismo y el Estado (Tilly, 1991: 26) que, al hacer saltar a la arena pública a una clase obrera organizada, amenazaban la preeminencia de las alianzas entre burguesía y aristocracia. Estos intelectuales construyeron las metateorías del nacionalismo, de la ciudadanía y de la modernización, de modo que el Estado llegó a ser visto como "portador de un proyecto moral» (Pérez Díaz, 1993: 92-93). En Alemania, parte de la sociología fue incluso más lejos; rechazó normativamente la diferenciación entre Estado y sociedad que la sociología inglesa y francesa habían considerado como condición de posibilidad del conocimiento sociológico (Lepenies, 1988: 235). Era en la propia diferenciación entre Estado y sociedad donde la sociología alemana, bajo la influencia de la filosofía del Estado de Hegel, había visto el origen de los males de la época; principalmente, la pérdida de valores (Lepenies, 1988: 237). En la medida en que Norbert Elias tiene una deuda con la concepción del Estado de Max Weber, puede considerarse que El proceso civilizatorio, al menos en lo que se refiere a su centrar el proceso de la civilización de las costumbres en la corte de las monarquías absolutas, se enraiza en el sustrato cultural de la sociología alemana anterior a 1945: un ethos académico permeado por valores nobles (Ringer, 1969: 38). La identidad de los profesores de universidad como una "aristocracia del espíritu» provenía de su alianza con la burocracia prusiana y el cuerpo de oficiales del ejército; la nobleza terrateniente tenía en ambos una presencia destacada (Ringer, 1969: 38).

La obra de Norbert Elias ha puesto en relación un proceso de psicosociología histórica y un proceso histórico de larga duración que es la constitución de los Estados europeos (Bourdieu, 1992: 69). A diferencia de la teoría de la civilización de Norbert Elias, la sociología histórica anglosajona hace abstracción de los cambios en las estructuras de personalidad relacionados con la construcción de los Estados europeos y con la diferenciación de mercados de capitales. La teoría de la decisión racional que Charles Tilly adopta implícitamente en sus estudios históricos presupone un grado de diferenciación y autocontrol emocionales tal como no se encontraban en períodos históricos anteriores a la diferenciación de mercados de capitales y de sistemas políticos (Tilly, 1986 y 1995). Las formas históricas de dominación, así como determinadas formas que puede llegar a tomar la violencia colectiva, no pueden comprenderse en un sentido únicamente instrumental. Del mismo modo que las formas de autoridad política han variado históricamente, la psicología social de la dominación ha ido al compás de cambios en las estructuras de la personalidad. La obra de 
Norbert Elias pone en relación la constitución de los Estados europeos, basada en el monopolio de la violencia, con cambios de orden psicosocial en el sentido de diferenciación e integración de las estructuras de la personalidad (Elias, 1989: 261 y ss.). En contraste con las continuas guerras por la posesión del territorio en la escindida sociedad feudal, los siglos de consolidación de las monarquías absolutas observaron una intensa «civilización» o contención del comportamiento, obligada por la creciente interdependencia entre los individuos, interdependencia cimentada en un poder central que monopoliza la violencia (Elias, 1989: 454). La coerción estatal, que disuade del recurso a la violencia, se incorporó como autocontrol emocional (Elias, 1989: 449 y ss.). En la obra de Elias, el acortesanamiento de la nobleza guerrera es el factor decisivo del proceso civilizatorio (Elias, 1989: 472 y ss.). Pero si se introduce un supuesto de diferenciación entre Estado y sociedad como proceso histórico, puede también proponerse que la incorporación de la coerción estatal como autocontención de las emociones tuvo lugar no en un "centro", como en la obra de Norbert Elias lo es la corte de las monarquías absolutas, sino en correspondencia con la diferenciación entre Estado y sociedad (Luhmann, 1989: 149-258). Como el mismo Elias señala, de forma algo contradictoria con respecto al resto de su obra, en el tiempo de las monarquías absolutas había predominado aún la coerción externa en la personalidad social de la nobleza cortesana, en forma de miedo a las sanciones derivadas del abandono a los propios impulsos; solamente con la aparición de la sociedad burguesa llegó a formarse una instancia de control endógeno de la acción (Elias, 1989: 484). En la sociedad estamental, la contención de las emociones se hacía necesaria únicamente dentro del propio estamento noble; en el trato con otros estamentos se vertían impulsos que no habían sido transformados por la estructura psíquica, pero que tampoco podían manifestarse dentro del propio estamento (Elias, 1989: 484). El trato entre personas pertenecientes a distintos estratos sociales estaba marcado, en mayor medida que el trato entre personas de distintas clases sociales en la sociedad burguesa, por la falta de reciprocidad y por la resistencia al acercamiento; por un bloqueo de la comunicación y una rigidez emocional sostenidas por el miedo a la contaminación y a la anomia: el extraño se vive entonces como sucio, anómico y menos humano (Elias, 1993: 17). La comunicación se restringía en gran medida al interior de cada estamento (Luhmann, 1986: 73). El consiguiente no darse cuenta de que otros son personas del mismo modo en que lo es uno mismo indica un problema clave, que puede tratarse tanto en un plano psicosocial como en un plano histórico. El limitado alcance de la identificación mutua, que se reducía al trato dentro del propio estamento, y la siempre posible quiebra abrupta de las «maneras civilizadas» en el trato con otros estamentos, indican que no puede hablarse todavía propiamente, por referencia a las postrimerías del Antiguo Régimen, de la diferenciación e integración de las estructuras de la personalidad que Elias llama «individuación» cuando llegan a ser endógenas; fuera del espacio de la corte, al desaparecer el miedo a la coerción de los pares, las «maneras civilizadas» se des- 
vanecían (Elias, 1989: 484). Aunque como proceso pudo haber tenido su comienzo en el tiempo señalado en El proceso civilizatorio, fue solamente con la diferenciación entre Estado y sociedad, es decir, con la quiebra del Antiguo Régimen, cuando la individuación se constituyó en su forma propia (Elias, 1987: 10). El paso de la coerción externa a una modelación de la acción endógena y diferenciada según la esfera de acción se habría dado no con el acortesanamiento de la nobleza guerrera, sino con la diferenciación de campos de acción respecto al monopolio del poder político: los mercados de capitales, el sistema de estratificación social y los campos de la cultura y la ciencia, entre ellos. Las sociedades estamentales, por estar estratificadas en compartimentos estancos que solamente se comunicaban unos con otros en forma de lazos de clientelismo y mecenazgo, habían acuñado la personalidad típica de cada estrato en forma de una combinación de identidades fijas. Con la aparición de sociedades funcionalmente diferenciadas y sin centro político integrador, la diferenciación e integración de personalidades que habían de oscilar entre esferas de acción estructuralmente diferenciadas se convirtió en el cimiento de un espacio público que hacía posible la identificación mutua entre extraños de distinto origen social (Brandenburg y Marx, 1993: 71-73).

Al menos hasta la segunda mitad del siglo XVII, las cortes europeas eran al mismo tiempo Estado y sociedad; aunaban la administración del Estado y la sociedad cortesana. Las tensiones entre la burguesía y la corte que condujeron a la revolución inglesa de 1640/41 desembocaron en la institucionalización de una oposición dentro del sistema político, por la cual las tensiones políticas llegaron a resolverse por cauces constitucionales (Luhmann, 1989: 82). En otros términos, se diferenció un sistema político respecto de la sociedad cortesana y de sus tensiones por la precedencia en el sistema de estratificación social. En Europa continental, por el contrario, la nobleza continuó en torno al Estado como nobleza de toga que monopolizaba las posiciones burocráticas más importantes, en alianza con fracciones de la burguesía, especialmente la burguesía de la educación. El final del Antiguo Régimen fue una encrucijada en la historia europea durante la cual, según se constituyeran o no alianzas entre aristocracia y burguesía, se inclinó la balanza del lado de la diferenciación entre Estado y sociedad (Inglaterra, Países Bajos, Francia en menor medida) o del lado del cuasimonopolio del Estado por parte de la aristocracia y de redes de patronazgo y clientelismo con ella aliadas (Alemania, España e Italia) (Luhmann, 1989: 27). Allí donde no hubo una ruptura abrupta con el Antiguo Régimen, la sociedad siguió teniendo su vértice y principio de estratificación en un Estado desde el que se tejían redes de patronazgo. El procedimiento político-administrativo del ennoblecimiento regulaba tanto el acceso a posiciones burocráticas como la estratificación social (Luhmann, 1989: 82). El siglo XIX y parte del XX de Alemania, país en que se centra el estudio que sigue, ha basculado entre la diferenciación estructural de mercados de capitales y la patrimonialización del Estado por una nobleza aliada con fracciones de la burguesía. 


\section{LA CONSTITUCIÓN DE UN ESTAMENTO \\ EN LA CELEBRACIÓN RITUAL DE LA MUERTE: LOS HERMANOS STAUFFENBERG Y EL CÍRCULO DE STEFAN GEORGE}

Según Conceptos históricos fundamentales (Koselleck, Conze et al.), algunos conceptos políticos alemanes procedentes del Antiguo Régimen se caracterizan por significados abstractos que van más allá de la esfera política (Koselleck, 1992, vol. 7: 300). El significado de conceptos franceses similares, por el contrario, es literal y únicamente político (Koselleck, 1992, vol. 9: 325). Estas diferencias en el uso del lenguaje político se pusieron de manifiesto en la reacción de la aristocracia alemana ante el Tratado de Versalles. Según documentos y obras literarias que datan de los años posteriores a la derrota en la primera guerra mundial, ésta fue interpretada por el estamento político y social aristocrático en términos de deshonor (Hoffmann, 1992: 31). El choque moral sufrido, tal como se encuentra documentado en las biografías de numerosos nobles alemanes, no se explica únicamente por una pérdida de recursos y capital (Van Roon, 1967). Durante las negociaciones que tuvieron lugar antes de la firma del Tratado de Versalles, y también en años posteriores, durante las negociaciones acerca de la reparación de los costes de la guerra y de las normas de derecho internacional, hubo claras diferencias en el uso del lenguaje político. En 1918, los gobiernos francés y británico demandaron a la Alemania derrotada reparación económica para compensar problemas financieros internos provocados por la guerra (Kent, 1989: 17). Por parte de los aliados, se trataba de una negociación de intereses económicos y políticos. Francia pedía, literalmente, una «reparación por los costes de la guerra» (Kent, 1989: 25). Las demandas de «reparación por los daños causados» del gobierno francés se referían al daño personal y material infligido a la población francesa durante la ocupación alemana (Kent, 1989: 20). La opinión pública francesa exigió posteriormente que Alemania se hiciese cargo de problemas presupuestarios de Francia que eran debidos a la guerra, y el gobierno francés, forzado por el déficit, tomó en cuenta estas demandas (Kent, 1989: 25). El término «reparación por los daños causados» se interpretó de otro modo desde las concepciones del honor que son propias de la aristocracia. Como evidencian numerosos discursos patrióticos, la derrota no fue interpretada en términos puramente políticos y económicos, sino que se recurrió a un lenguaje figurativo claramente distinto del empleado por el gobierno y la opinión pública franceses (Wolters, 1927: 2). Su significación estaba enraizada en el "uso ritual de la violencia» (Elias), y su carácter figurativo habría de desaparecer con los rituales que la sustentaban. Norbert Elias ha caracterizado al estamento social y político que cuasimonopolizaba el alto funcionariado alemán entre 1871 y 1918 como una «sociedad de quienes pueden dar reparación por las armas» (Elias, 1989: 63). Los duelos eran una forma de "uso ritual de la violencia» que diferenciaba a quienes podían ser retados a duelo de quienes no, de modo que el estamento 
noble monopolizaba la violencia legítima. Los rituales sociales y políticos transformaban la pura coerción en legitimidad política. De ahí que la violencia estatal no fuera percibida como pura «organización de la coerción», por emplear términos de Tilly que no podrían aplicarse a este estudio. En los escritos de altos funcionarios y militares alemanes acerca de la derrota aparece un uso del lenguaje que no es literal, sino figurativo. En una carta escrita por el general Beck tras el armisticio aparece el verbo untergehen (Foerster, 1949: 12), que en el contexto estricto de la carta puede traducirse como «decadencia», pero cuyo significado histórico ha tenido una densidad que el lector moderno, sobre todo si no es de lengua alemana, puede desconocer. Después de escrita esta palabra, Beck continúa en la siguiente frase con una analogía entre el organismo humano y la sociedad alemana que ya había empleado antes en otro lugar de su carta. Como otros conceptos que aparecen en Conceptos históricos fundamentales, untergehen tiene significaciones abstractas que van más allá del terreno político. Si, por una parte, esta palabra significa decadencia de imperios o sociedades, también se ha empleado con la significación de muerte de un individuo (Grimm, 1936: 1574). El sustantivo Untergang y su correspondiente verbo untergehen han perdido en los diccionarios modernos uno de sus significados históricos, que es «morir»y «muerte», según se trate de un sustantivo o de un verbo (Brockhaus, 1980). El volumen del diccionario filológico en que se ha encontrado el significado histórico se editó en 1936. El significado perdido es esencial para comprender los textos analizados en este estudio. La palabra Untergang ha aparecido con frecuencia en textos políticos; En Conceptos históricos fundamentales aparece en el índice analítico con numerosas entradas, no como concepto político ella misma, sino asociada a conceptos políticos. Por otra parte, Norbert Elias señala que pocos ideales nacionales contienen tantas alusiones a la muerte como el ideal alemán (Elias, 1989: 429-430). Las tristes canciones, entonadas y repetidas una y otra vez durante las celebraciones políticas, de hombres que iban al encuentro de la muerte, reflejan una pauta tanto de la sociedad como de la conciencia (Elias, 1989: 431).

El significado de palabras como "sacrificio» y «decadencia» en la biografía del conde Stauffenberg no es únicamente político, sino que se encuentra profundamente enraizado en celebraciones rituales de la muerte, tanto sociales como políticas, repetidas desde la más temprana infancia. La interpretación de material biográfico es, por tanto, relevante para comprender los matices del lenguaje político del Antiguo Régimen. La derrota en la primera guerra mundial dejó en Claus una impresión muy profunda, que le llevó a interrogarse durante todo el resto de su vida por sus causas (Mommsen, 1997). Cabe preguntarse por qué se hizo de la derrota y del fin del imperio una interpretación moral, de modo que en algunos casos (en el de Claus no hay referencias concretas y claras) se interpretara a la luz de una crisis biográfica individual. En expresión de Van Roon acerca de Peter Yorck, conde de Wartenburg, aunque no documentada: «Los años de la posguerra, en los cuales todo orden estructurado pareció disolverse, y el ansia de decadencia (Untergangsverlangen) y los 
deseos vitales se entremezclaban, fueron el tiempo en que Peter Yorck aprendió a conocer el mundo" (Van Roon, 1967: 79)2. La expresión traducida como "anhelo de decadencia» tiene, al mismo tiempo, una posible connotación de «anhelo de muerte». El lenguaje de la frase citada posee no solamente un contenido político, sino también una latencia que atañe al sí mismo. Éste no se puede considerar por tanto como enteramente individualizado. Norbert Elias ha escrito lo siguiente sobre la reacción de la aristocracia alemana ante la derrota: "Como resultado de una amenazante pérdida de poder, cualquier cosa que esto signifique, los miembros de estratos dominantes sufren un profundo daño en la imagen de sí mismos y con frecuencia la enter quiebra de todo lo que daba significado y valor a sus vidas» (Elias, 1990: 462). Elias explicaba esta manifestación por la desaparición de rituales sociales y políticos dadores de sentido, los cuales transformaban la violencia en legitimidad política y sentido de la vida al mismo tiempo (Elias, 1990: 462). La palabra untergehen aparece por primera vez en la biografía de Stauffenberg con ocasión de haberse anunciado el armisticio: «Mi Alemania no puede decaer (untergehen) - aunque ahora esté hundida - debe alzarse fuerte y grande otra vez - aún hay un Dios» (Hoffmann, 1992: 31). En sus cartas, Claus se refiere a la muerte con esta misma palabra (Giessler, 1989: 552-564). Cabe preguntarse si esta doble significación es simultánea o alternativa, porque la traducción de expresiones tales como untergängliche Haltung des Offiziers, des Herren (Giessler, 1989: 563), que podría traducirse como «el ser para la muerte de los oficiales, de los señores», o como su "postura ante la muerte», plantea dificultades. Es la misma dificultad que se ha encontrado al traducir la expresión Untergangsverlangen, citada un poco más arriba. Son problemas metodológicos relacionados con la constitución del significado en el uso concreto de las palabras. Según el diccionario filológico de los hermanos Grimm, Untergang significa "decadencia» cuando se refiere a una sociedad o a una unidad política, y «muerte» cuando se refiere a personas, pero las frases siguientes muestran una simultaneidad de significado: «Si inculcamos a nuestros hijos que sólo la lucha continua y el continuo esfuerzo por la renovación nos pueden salvar de la decadencia (Untergang), y esto tanto más cuanto que ya se ha alcanzado mucho, y que la perseverancia, la resistencia y la muerte son idénticas, entonces habremos logrado cumplir la mayor parte de nuestro deber educativo nacional» (Hoffmann, 1992: 215-216). Estas frases se han tomado de una carta escrita por Stauffenberg a su mujer desde el frente el 16 de junio de 1940. La familia, como puede verse, no se situaba en un reducto privado: se hace referencia a un «deber educativo nacional» de los padres. Del mismo modo, la significación de la muerte que había de inculcarse a los hijos tampoco se limitaba a la esfera privada. La

La obra de Gerd van Roon sobre el círculo de Kreisauer contiene una corta biografía de cada uno de sus miembros (Van Roon, 1967: 56-209). En las de Helmuth James, conde de Moltke, y Peter Yorck, conde de Wartenburg, en particular, las referencias a una crisis biográfica tras la derrota son muy claras. 
constitución de la muerte como horizonte de significado (Husserl) desde la más temprana infancia, no puede diferenciarse en la biografía de Stauffenberg de los esfuerzos por mantener unido, aun después de la caída del imperio, el estamento aristocrático. Por otra parte, el lenguaje político transformaba la pura angustia ante la muerte en un horizonte de sentido. El significado de la expresión untergängliche Haltung, tal como aparece en una carta fechada el 6 de febrero de 1939, se refería no solamente a la muerte de un individuo, sino también a la constitución de un estamento aristocrático diferenciado por su «ser para la muerte».

El significado de untergehen está enraizado en ritos sociales de interacción que pervivieron aún después de la caída del imperio. Claus nació en 1907, prematuro de ocho meses, junto con un hermano gemelo que murió al día siguiente (Hoffmann, 1992: 21-22). Cuando Claus creció y pudo comprenderlo, sintió profundamente la muerte de su hermano, a quien recordaba en ocasiones señaladas como su primera comunión (Hoffmann, 1992: 22). Siempre que veía una cruz, se arrodillaba y rezaba. Después de ponerse en pie, decía: "he pensado en mi hermano pequeño» (Hoffmann, 1992: 478). En 1909 cayó seriamente enfermo (Hoffmann, 1992: 22). Cada cierto tiempo, y hasta bien entrada la edad adulta, caía enfermo y debía guardar cama. A comienzos de 1911 soñaba frecuentemente con la muerte (Hoffmann, 1992: 22). Durante el mes de julio de 1912 llevaba flores a su madre cada día para que ella las colocara sobre la tumba de su hermano (Hoffmann, 1992: 478). Aquí hay ya, no una celebración privada de la muerte por parte de un niño, sino un rito de interacción en germen (Goffman), entre un niño y su madre. A diferencia de lo que Norbert Elias escribe sobre las sociedades occidentales contemporáneas (Elias, 1987: 26), lo que rodeaba a la muerte no era entonces mantenido fuera de la sociedad, sino que se creaban ritos de interacción que la celebraban. En 1918, la madre de Claus, Constance, escribió al poeta Rilke con ocasión de la muerte del doctor Stauffenberg, pariente suyo que como médico había tratado al poeta (Hoffmann, 1992: 39). Quería saber si su último libro, sobre el que había hablado mucho con el doctor Stauffenberg, había sido ya publicado. Escribió también que el día del funeral del doctor Stauffenberg estuvo en su habitación leyendo un libro dejado junto a su mesilla: quería volver a compartir su mundo (Hoffmann, 1992: 39). Rilke respondió a Constance preguntándole, a su vez, por el libro dejado junto a la mesilla del doctor Stauffenberg, ya que estimaba mucho su juicio crítico. Con la carta le envió copia de uno de sus últimos poemas, titulado «Requiem por la muerte de un niño». Constance le respondió citando los títulos y autores que había sobre la mesilla, ninguno de los cuales era Rilke. En una carta posterior, el poeta le envió a Constance otros poemas inéditos, señalando que su elección había estado determinada por lo que le hacía sentirse obligado hacia la condesa, esto es, la muerte del doctor Stauffenberg (Hoffmann, 1992: 40). Ella le dio las gracias por los poemas, añadiendo que podrían serle de ayuda, como madre de tres hijos, en los duros tiempos que se avecinaban. Según Norbert Elias, «el 
hecho de morir fue en otra época un asunto mucho más público que en la actualidad (...) eran acontecimientos sociales, menos privatizados de lo que lo están hoy en día» (Elias, 1987: 26-27). La vacuidad de los ritos funerarios contemporáneos, que no son ritos en el sentido antropológico de la palabra, pone de manifiesto esta privatización de la muerte (Elias, 1987: 34). En los episodios arriba citados, por el contrario, se le da a la poesía un uso ritual, como una manera de sobrellevar la muerte. Lo que rodeaba a la muerte no se ocultaba en un reducto privado, sino que, como en los episodios citados, se aludía con naturalidad a ella incluso en la correspondencia con una persona enteramente desconocida. La ocultación de los aspectos más crudos de la muerte en un reducto privado por completo ajeno a los encuentros sociales y a la esfera de lo público es un aspecto del proceso civilizatorio (Elias, 1989: 228). Por este mismo proceso, la legitimidad política se diferencia de todo lo que queda confinado en un reducto privado.

En la Alemania del primer cuarto de siglo, la celebración del nacimiento, el matrimonio y la muerte no eran acontecimientos privados o públicos en el sentido contemporáneo de la palabra (Dübing et al., 1988: 390). La significación misma de la muerte estaba relacionada con la legitimidad política. La latencia de significado presente en palabras como Untergang y expresiones como untergängliche Haltung, tal como aparecen en las cartas de Stauffenberg, se constituyeron en celebraciones políticas de carácter ritual en las que se difuminaban los límites entre lo público y lo privado. La declamación en público de poesía sobre la muerte sacrificial por el Estado aparece desde la adolescencia en la biografía de los tres hermanos Stauffenberg, con frecuencia durante celebraciones escolares, es decir, estatales. En 1920, Berthold y Alexander Stauffenberg representaron pequeños papeles en una representación de Empédocles, de Hölderlin (Hoffmann, 1992: 44). En 1922, Berthold escribió una redacción escolar sobre esta misma obra (Hoffmann, 1992: 44). Interpretó el suicidio de Empédocles arrojándose al Etna como un sacrificio ritual en el sentido de la religión griega antigua. La lección de la obra, según Berthold, es la necesidad de sacrificar la propia vida por una idea (Hoffmann, 1992: 44). Empédocles, la obra de Hölderlin contiene una elaboración de la acción política violenta como fuente de lo sagrado (Hölderlin, 1997), y está en los orígenes de la idea de nación alemana.

En los años veinte de este siglo, la figura del poeta conoció un revival, en parte debido a los escritos del círculo del poeta Stefan George (Text und Kritik, 1996). Empédocles es una celebración de la muerte escrita durante la invasión napoleónica (Hölderlin, 1997). El poeta fracasó en su intento de convertir la muerte de un individuo, un filósofo nacido en la colonia griega de Sicilia, en una "oda trágica» con relevancia política para la nación alemana. En la obra, el filósofo griego es una figura política carismática que cae en desgracia ante su pueblo. El drama inacabado se centra en el "sagrado camino de la muerte» de una figura aislada que trata de recobrar su gracia divina, por lo que la obra no alcanza la forma abstracta que deriva de la oposición entre dos figuras dramáti- 
cas. Por esta razón, el sentido de la muerte de Empédocles es ininteligible para el lector. En cualquier caso, la intención general del poeta queda clara en el esbozo de la obra: "Y de la muerte que purifica/aquélla que ellos eligieron en el momento justo,/resurgen, como Aquiles de la Estigia, los pueblos» (Hölderlin, 1997: 171). La muerte de Empédocles parece tener al mismo tiempo un significado político y un significado interno, pero ambos no llegan a estructurarse en una forma abstracta clara. La representación de la oda trágica de Hölderlin en la escuela puede considerarse como una celebración política, pero, al mismo tiempo, promueve la transformación interna de la experiencia de la violencia y la muerte que le da carácter de celebración ritual. Según R. Girard, la tragedia griega es un desvelamiento reflexivo, pero fracasado, de la transformación de la violencia en lo sagrado que llevaban a cabo los ritos sacrificiales de la Antigüedad (Girard, 1998: 104). W. Benjamin ha considerado que la poesía trágica griega descansa en la idea de sacrificio expiatorio (Benjamin, 1990: 95-96), y en este sentido puede considerarse que juega un papel sustitutorio respecto a los ritos sacrificiales de la Antigüedad. La oda trágica de Hölderlin puede considerarse también como sustitución de un rito. Empédocles es al mismo tiempo una víctima propiciatoria y una figura venerada. Según Girard, la víctima ritual concentra la violencia sobre su cabeza, y al morir hace que se transforme en gracia divina (Girard, 1998: 103). Tras la muerte de Empédocles, la crisis de legitimidad en que estaba inmersa Sicilia se resuelve en paz y fecundidad. Girard se aparta de la tradición antropológica que considera la tragedia griega como una continuación del ritual, pero admite que «el fracaso de la deconstrucción trágica acabe por conferir, en último término, un valor casi ritual a la tragedia en la cultura occidental» (Girard, 1998: 104). Los tres hermanos Stauffenberg estuvieron estrechamente vinculados al poeta desde su más temprana adolescencia. El círculo de amigos de Stefan George, designado por ellos mismos como "el estado", muestra la indiferenciación de la acción política que era propia de las postrimerías del Antiguo Régimen en Alemania: si bien era un estamento político y social en germen, no puede decirse que su acción fuera única y literalmente política. No estaba constituido como asociación ni poseía organización formal alguna (Lepenies, 1988: 268). Estaba compuesto por entre veinte y cuarenta adeptos procedentes de la burguesía educada (principalmente profesores de universidad y escritores), de la aristocracia del sur de Alemania y de la burguesía ennoblecida (Lepenies, 1988: 266). El círculo de Stefan George no se desenvolvía en la esfera pública, sino que, antes al contrario, George consideraba que la idea de Hölderlin, Schiller y otros autores de una "Alemania oculta", aún no realizada, debía mantenerse en secreto (Lepenies, 1988: 268). Stefan George continuó la elaboración de los ideales nacionales alemanes que Hölderlin había comenzado. En 1928, el círculo editó El poeta como líder en los clásicos alemanes, de uno de sus miembros, Max Kommerell, donde se celebra a Hölderlin como el poeta de la "Alemania escondida». Según Kommerell, la poesía de Hölderlin es la principal elaboración literaria de un ethos profundamente enraizado en el pueblo alemán que 
concierne a la muerte (Kommerell, 1928: 405). Y se cita el verso de Hölderlin «(...) pues mi corazón pertenece a los muertos» (Kommerell, 1928: 405). Hölderlin encontró en la tragedia griega un reflejo de su experiencia interna, la cual no se diferencia claramente de sus ideales nacionales. La idea de sacrificio la encontró el poeta en la obra de su contemporáneo y amigo Schiller, quien en Los dioses de Grecia escribió: "Lo que ha de ser inmortal en el canto/debe decaer en la vida» (Kommerell, 1928: 405). Con ayuda de la religión griega antigua, que gira alrededor de ritos de sacrificio, Hölderlin dio forma a este ethos latente en su interior. Kommerell parece referirse a la estructura de un sí mismo que es más que el individuo aislado, pero no es claro que la aparente estructura sea verdaderamente tal, y no un simulacro conscientemente elaborado. Kommerell considera que en la palabra "sacrificio», tal como Hölderlin la emplea, hay una forma latente que un lector alemán comprende de inmediato (Kommerell, 1928: 459). Opfer sería una "palabra que obliga», despertando en el pueblo alemán "fuerzas» hasta entonces dormidas. En términos manifiestamente similares a los de Freud (es posible que procedentes de una lectura de Freud), Kommerell describe así la latencia en el lenguaje: «(...) la palabra Volk tiene para Hölderlin un significado manifiesto y otro latente (...) que es el pueblo en su esencia sagrada» (Kommerell, 1928: 466). El significado latente de Volk se refiere a su encarnación en un estamento consagrado en la guerra, porque la muerte sacrificial de una aristocracia la constituye como estamento, esencia del pueblo alemán en su sentido más profundo y verdadero (Kommerell, 1928: 467). Lo que separa a este "estamento diferenciado" del pueblo en su sentido literal es el sacrificio y la muerte (Kommerell, 1928: 468). Esto coincide con lo que Koselleck señala en Conceptos históricos fundamentales con respecto a esta misma palabra: la palabra Volk adquiere a veces una significación abstracta que no se limita a la esfera política (Koselleck, 1992, vol. 9: 300). La legitimidad de esta palabra, es decir, su significado latente, habría de constituirse en el uso ritual de la violencia (Elias). En otros términos, la guerra es fuente de legitimidad política. Refiriéndose a "Archipelagus», un poema de Hölderlin, Kommerell escribe: «El designio oculto del futuro alemán, que para nosotros esconde Archipelagus, es la deificación de un pueblo entero en la guerra. Este poeta atormentado por el pánico vital, a quien incluso un soplo de viento daña, ha celebrado sin miedo la guerra como la realidad popular más elevada... ciertamente sólo aquella guerra propia de un pueblo responsable. Es el pueblo tal como Hölderlin lo ha pensado: un pueblo por entre el cual caminan los dioses engendrando sus héroes, un pueblo cuya vida lo hace asemejarse a los dioses hasta en sus acciones más sencillas, posee una precedencia de rango absoluta. Pueblo en este sentido sólo puede serlo uno en cada época... todos los otros pueblos lo son por tanto de segundo orden, y entre ellos el pueblo único está como el héroe entre los hombres comunes» (Kommerell, 1928: 474). La idea de "el pueblo en armas» procede de Gneisenau, el vencedor de Napoleón. Los hermanos Stauffenberg, sus descendientes, le seguían al legitimar al pueblo en armas, liderado por el cuerpo de oficiales, constituido en vér- 
tice de un estamento dominante, como la encarnación más propia de la nación (Hoffmann, 1992: 180). Un estudio sobre Gneisenau, firmado por Rudolf Fahrner pero escrito en común por varios miembros del círculo, es, según el biógrafo de Stauffenberg, su manifiesto (Hoffmann, 1992: 163). El libro fue redactado durante los años de entreguerras, circuló un tiempo en ediciones restringidas, y fue finalmente publicado en 1942 (Hoffmann, 1992: 163). No es un manifiesto político en el sentido usual del término, pues no fue presentado públicamente como tal, de acuerdo con el ideal de la "Alemania oculta", pero su contenido sí lo es. El libro puede leerse como la llamada a una insurrección (Erhebung) que reparase la derrota en la primera guerra mundial y, las consecuencias del Tratado de Versalles para la economía y la sociedad alemanas. Gneisenau había tratado de reproducir en Alemania algunos aspectos de la Revolución francesa, en la forma modificada de una «revolución desde el trono», al mismo tiempo que luchaba contra la grande armée. Según Rudolf Fahrner, la Revolución francesa había despertado en el pueblo fuerzas latentes que son fuente de una forma de derecho más alta que todas las constituciones (Fahrner, 1942: prólogo). Aquí aparece otra muestra de la indiferenciación de la legitimidad política respecto de las «fuerzas latentes en el pueblo», es decir, de la violencia ritualizada que da significado a los términos Erhebung y la palabra sinónima Aufhebung (Fahrner, 1942: 15-16). Se trata de una forma de legitimidad claramente distinta de la racional-legal. La palabra Erhebung significa, por una parte, «insurrección» (Grimm, 1854: 664). Pero la misma palabra significa también, según el diccionario de Grimm, «elevación» o "celebración», en sentido con frecuencia religioso (Grimm, 1854: 664). Según el diccionario filológico de Grimm, cuyo volumen tercero fue publicado en 1854, el significado abstracto de erheben es el más frecuentemente empleado. De hecho, en el diccionario aparecen varias citas de la biblia de Lutero que lo ilustran. La siguiente frase de Gneisenau muestra el significado abstracto de la palabra: "No siempre han sido los ejércitos quienes han salvado al trono y al estado. Con frecuencia era el amor por sus señores de pueblos elevados en el espíritu (...) No hay elevación del corazón (Herzenserhebung) sin voz poética (...)» (Fahrner, 1942: 51). De acuerdo con la definición antropológica del ritual (Turner), los dos significados opuestos de la misma palabra son ensamblados por el uso ritual de la violencia, del que queda un rastro en el lenguaje. El estudio sobre Gneisenau parece estar escrito para ser leído en voz alta en un acto público: las palabras Erhebung y Aufhebung se repiten con mucha frecuencia, cada vez con un sentido distinto, y la redacción es deliberadamente simple, como si se tratara de narrar una leyenda a un público no demasiado culto.

En Cuatro discursos sobre la patria, de Friedrich Wolters, aparecen ideas similares a las de otras publicaciones del círculo de Stefan George (Wolters, 1927). El doctor Wolters, profesor de universidad y veterano de guerra, pronunció un discurso en el funeral por los caídos de la Universidad Christian Albrecht, de Kiel, el 22 de noviembre de 1925. El texto, recogido en el libro citado, es una muestra clara de celebración de la muerte en un acontecimiento 
público. El título del discurso es «Sobre el significado de la muerte sacrificial (Opfertod) por la patria», y su tema la constitución histórica del pueblo alemán a través de la muerte sacrificial de su estamento dominante. El discurso comienza con una referencia a la deshonrosa derrota en la primera guerra mundial (Wolters, 1927: 9). Después se hace una síntesis de la historia del pueblo alemán como constituido en la guerra: «(...) El guerrero se sacrificaba no por su sociedad, sino por su líder, y si éste caía, sus seguidores morían en la venganza o se daban muerte a sí mismos, para no sobrevivirle. Debido al deber mutuo de la sangre o de la comunidad de juramento, el líder se sacrificaba por su tropa, el príncipe por su linaje, el rey por su pueblo (...)» (Wolters, 1927: 21-22). La palabra Opfertod («muerte sacrificial») se repite con mucha frecuencia, como es usual en las alocuciones orales. Su significado está relacionado tanto con la acción política como con lo sagrado. Mientras que en algunas frases el sacrificio aparece como un esfuerzo por concentrar recursos de coerción y de capital en manos del Estado alemán (Wolters, 1927: 27), su significado aparece en otros lugares del texto como relacionado con lo sagrado. La muerte en lucha de un guerrero otorga gracia, en el sentido religioso de la palabra, a la dominación estamental: «Antaño, la exigencia de poner a prueba a la persona y de ser recibido en la tropa eterna de los héroes a través de la muerte en lucha, guardaba un parentesco interno con las formas cristianas de la sacralidad personal y de la lucha universal del espíritu" (Wolters, 1927: 23). Según Wolters, los orígenes históricos del Estado alemán están en un estamento constituido en la muerte sacrificial de sus miembros (Wolters, 1927: 21-22). Los restantes textos contenidos en Cuatro discursos sobre la patria, pronunciados también con ocasión de distintos acontecimientos públicos, tienen como tema a Goethe y otros poetas alemanes, y en ellos aparece una celebración similar de la muerte.

Las ideas contenidas en los textos analizados no son ajenas a la carrera de los tres hermanos Stauffenberg en la alta función pública alemana: Claus como oficial de Estado Mayor, Berthold como doctor en Derecho adscrito al alto mando de la marina y Alexander como profesor de universidad (Hoffmann, 1992). Después de la derrota en la primera guerra mundial y el subsiguiente final del Antiguo Régimen, la aristocracia alemana había perdido el poder político y administrativo, con la sola excepción de una posición en el ejército que continuaba siendo privilegiada (Elias, 1989: 282). Las celebraciones políticas del imperio desaparecieron, y solamente restaron ritos sociales de interacción y textos en torno a la muerte en la guerra (Düding, 1988: 11). Pero incluso si el imperio había desaparecido, en los escritos de la aristocracia y de la burguesía de la educación aliada con ella se encuentran referencias a la constitución por venir de un estamento que habría de consagrarse en la guerra. Los textos analizados trataron de recrear en el lenguaje rituales desaparecidos, no solamente los propios de una sociedad estamental, sino también ritos de sacrificio de la antigua Grecia. Entre la primera y la segunda guerra mundial tuvieron lugar las últimas luchas de la aristocracia alemana por preservarse como estamento 
diferenciado, indisolublemente social y político. Durante la primera guerra mundial había tenido lugar una revolución en la marina alemana, además de una crisis de legitimidad más difusa en el frente. Según el general Lüdwig Beck, en la retaguardia de las filas alemanas hubo una crisis de autoridad, y a ella atribuye la derrota (Foerster, 1949: 12). En una carta ya citada, escrita poco después del armisticio, Beck considera que la revolución política que había tenido lugar en la marina era solamente manifestación de una enfermedad del entero organismo social por la que parte de las tropas, como inoculadas por un bacilo, no resistía lo necesario (Foerster, 1949: 12). La correspondencia entre el conde Stauffenberg y Georg von Sodenstern a comienzos de 1939 ilustra los esfuerzos posteriores de la aristocracia por mantener su diferenciación ritual como encarnación de la autoridad del Estado: "La disposición a morir separa al soldado de toda otra comunidad humana» (Hoffmann, 1992: 178). Sodenstern y Stauffenberg consideraban que la esencia del ser soldado se encarnaba en los oficiales, en su mayor parte de origen noble: «El son para la muerte de los oficiales (untergängliche Haltung), es propio de señores» (Giessler, 1989: 563). El significado de untergängliche Haltung, y en general de las palabras Untergang y untergehen tal como aparecen en las cartas de Stauffenberg, se refiere simultáneamente a la muerte y a la constitución a través de la muerte de un estamento aristocrático que encarna la idea de la nación alemana. La frase siguiente, procedente de la misma carta, puede interpretarse en este sentido: "Tenemos que luchar por nuestro pueblo y por el Estado mismo, siendo conscientes de que la esencia del ser soldado y su agente, el cuerpo de oficiales, es el portador esencial del Estado y la encarnación misma de la nación» (Giessler, 1989: 563). El sentido de estas cartas se comprende en el contexto de las luchas entre el partido nazi y el ejército alemán por el control del Estado. Pero la semántica que las cartas, escritas a comienzos de 1939, contienen, se había diferenciado ya de la organización de la coerción. El ritual imbrica la organización de la coerción y una semántica. Las cartas, y el artículo al que se refieren, jugaron su papel en la lucha política, pero su lenguaje se había desligado de la ritualización de la violencia que le daba sentido. Únicamente la aristocracia comprendía ya este sentido latente. Los oficiales más viejos, veteranos de la primera guerra mundial, habían percibido una crisis de legitimidad (Giessler, 1989: 556). En el pasado, la condensación de significados relacionados tanto con la violencia política como con lo sagrado había sido llevada a cabo por el ritual (Turner, 1988: 62). La declamación de poesía era un componente relevante de las celebraciones sociales y políticas (Düding et al., 1988: 237-258).

A través del ritual de las celebraciones políticas, la muerte se va constituyendo como horizonte de sentido en la biografía del conde Stauffenberg y de sus hermanos. En Claus, particularmente, puede rastrearse desde una edad temprana hasta su propia muerte, después de haber atentado contra Hitler en el curso de un golpe de Estado que tuvo lugar el 20 de julio de 1944, fallido como el atentado con bomba. Su muerte puede considerarse como un sacrifi- 
cio ritual, que es una de las formas que puede tomar el suicidio altruista, según Durkheim (Durkheim, 1993: 242). Es la acción que empuja a la muerte a quien no se distigue a sí mismo del estamento que encarna, y que por tanto está relacionado con una falta de individuación. El golpe de Estado tenía al mismo tiempo una significación interna profunda.

\section{CONCLUSIONES}

Los términos arriba analizados no pueden ser entendidos en términos únicamente políticos; su significado latente se encontraba incorporado en el sí mismo a través de celebraciones rituales de la violencia y la muerte en la guerra que absorbían al individuo. Las palabras referidas a la fenomenología de la muerte tenían al mismo tiempo un significado político. Esto al menos en lo que se refiere a la cultura política de la aristocracia. Que la cultura, y no solamente la cultura política, surge de la experiencia de la violencia y la muerte en la guerra, no es una idea ajena a la literatura y la filosofía alemanas. Una lectura atenta de Conceptos históricos fundamentales lo muestra. Incluso en autores de lengua alemana claramente alejados de la cultura política residual del Antiguo Régimen puede encontrarse un rastro de ella. Algunos escritos de Freud contienen una cultura en torno a la muerte similar a la de otros autores de lengua alemana, desde Schiller y Hölderlin hasta Thomas Mann (Freud, 1994: 33-60). En lugar de negar la muerte, manteniéndola fuera de la sociedad como carente de sentido, Freud la convierte en horizonte de sentido. La interpretación acerca de la negación de la muerte usual en las sociedades occidentales, escrita en 1914, es al mismo tiempo una variación cultural. En otro lugar cita los versos de Schiller: "lo que ha de ser inmortal en el canto decae (untergehen) en la vida» (Freud, 1994: 548).

Pero esta cultura acerca de la muerte perdió su significado al desaparecer el uso ritual de la violencia que la había sustentado. Según la antropología estructural, el ritual es fuente de significados culturales configurados por la oposición entre dos significados literales. Las celebraciones públicas de la guerra y la muerte son en este sentido sustitutivos o equivalentes funcionales del uso ritual de la verdadera violencia y de la verdadera muerte. Su papel es, por tanto, similar al de la "sustitución de la víctima» en los ritos antiguos de sacrificio (Girard, 1998) y en la tragedia griega (Benjamin, 1990). La declamación de poesía y el canto eran componentes importantes de las celebraciones sociales y políticas (Düding et al., 1988: 237-258). La oda trágica Empédocles y el resto de los textos estudiados son sustituciones de este tipo. Las celebraciones políticas eran, como la guerra, un tiempo fuera de la estructura social que la reproducía. Untergang se refiere al ritual ponerse fuera de la sociedad, ya fuera en la guerra o en las celebraciones sociales y políticas que la recreaban. La violencia y la guerra introducen una discontinuidad en las rutinas sociales, y quien las experimenta está por un tiempo fuera de la sociedad: con ello se con- 
vierte en un ser excepcional que ha pasado por una situación excepcional. El ritual separa a quienes pasan por él de quienes no lo han pasado. Bourdieu ha definido lo ritos de institución como acciones de consagración que crean un grupo separado y sagrado, una nobleza (Bourdieu, 1989: 101). Es por esta razón que la guerra ha sido históricamente tal fuente de legitimidad política.

\section{BIBLIOGRAFÍA}

Benjamin, W. (1990): El origen del drama barroco aleman, Madrid, Taurus.

Bourdieu, P. (1982): Ce que parler veut dire, París, Fayard.

- (1989): La noblesse d'état. Grandes écoles et sprit de corps, París, Seuil.

- (1992): Réponses. Essai d'anthropologie réflexive, París, Seuil.

BrandenburG, A. G., y Marx, P. (1993): «Politische Modernisierung als Revolution von oben. Zur Soziologie der deutschen Sonderentwicklung», en K. Plake y W. K. Schulz (Hrsg.), Entillusionierung als Programm. Beiträge zur Soziologie von Shmuel N. Eisenstadt, Weinheim, Deutscher Studien Verlag.

Brockhaus Wahrig Deutsches Wörterbuch (1980): Stuttgart, Deutsche Verlags Anstalt.

Crouch, C. (1986): «Sharing Public Space», en J. A. Hall (ed.), States in History, Oxford, Blackwell.

Deutsches Wörterbuch von Jacob und Wilhelm Grimm (1984): München, Deutscher Taschenbuch Verlag.

Düding, D.; Friedemann, P., y Münch, P. (eds.) (1988): Öffentliche Festkultur. Politische Feste in Deutschland von der Aufklärung bis zum Ersten Weltkrieg, Hamburg, Rowohlts enzyklopädie.

Durkheim, E. (1993): Le suicide, París, Presses Universitaires de France.

Elias, N. (1987): Die Gesellschaft der Individuen, Frankfurt, Suhrkamp.

- (1987): La soledad de las moribundos, Madrid, FCE.

- (1989): El proceso de la civilización, Méjico, FCE.

- (1990): Studien über die Deutschen. Machtkämpfe und Habitusentwicklung im 19. und 20. Jahrhundert, Frankfurt, Suhrkamp.

EliAS, N., y SCOTSON, J.L. (1993): Etablierte und Aussenseiter, Frankfurt, Suhrkamp.

FAHRNER, R. (1942): Gneisenau, München, Delfin Verlag.

Freud, S. (1994): Fragen der Gesellschaft. Ursprünge der Religion, Studienausgabe, band IX, Frankfurt, Fischer.

Giessler, K. V. (1989): «Briefwechsel zwischen Claus Graf Stauffenberg und Georg von Sodenstrn von Februar/März 1939. Gedanken zum Wesen des Soldatentums», en F. P. Kahlenberg (ed.), Aus der Arbeit der Archive. Beiträge zum Archivwesen, zur Quellenkunde und zur Geschichte, Boppard am Rheim, Harld Boldt Verlag, pp. 552-564.

GIRARD, R. (1998): La violencia y lo sagrado, Barcelona, Anagrama.

Hoffmann, P. (1992): Claus Schenk, Graf von Stauffenberg und seine Brüder, Stuttgart, Deutsche Verlag.

Hölderlin, F. (1997): Empédocles, Madrid, Hyperion.

Kent, B. (1989): The Spoils of War. The Politics, Economics and Diplomacy of Reparations 19181932, Oxford, Clarendon Press.

Kommerell, M. (1928): Der Dichter als Führer in der deutschen Klassik. Klopstock, Herder, Goethe, Schiller, Jean Paul, Hölderlin, Berlín, Georg Bondi.

Koselleck, R.; Conze, W, y Brunner, O. (1992): Geschichtliche Grundbegriffe. Historisches Lexicon zur politisch-sozialen Sprache in Deutschland, Stuttgart, Klett-Cotta.

Lepenies, W. (1988): Between Literature and Science: The Rise of Sociology, Cambridge y París, Cambridge University Press y Éditions de la Maison des Sciences de l'Homme. 
LuHmann, N. (1989): Gesellschaftstruktur und Semantik. Studien zur Wissenssoziologie der modernen Gesellschaft, Bd. III, Frankfurt, Suhrkamp.

Mommsen, H. (1997): Le national-socialisme et la société alemande, París, Maison des Sciences de l'Homme.

Pérez DíAz, V. (1993): La primacía de la sociedad civil, Madrid, Alianza.

Ringer, F. (1969): The Decline of the German Mandarins. The German Academic Community 1890-1933, Cambridge (Mass), Harvard University Press.

Text und Kritik (1996): número monográfico sobre Hölderlin, München, ed. Text und Kritik.

Tilly, C. (1986): The Contentious French, Cambridge (Mass.), Harvard U. P.

- (1990): Coerción, capital y los Estados europeos, 990-1990, Madrid, Alianza.

- (1991): Grandes estructuras, procesos amplios, comparaciones enormes, Madrid, Alianza.

- (1995): La revoluciones europeas, 1492-1992, Barcelona, Crítica.

TURNER, V. W. (1989): El proceso ritual. Estructura y antiestructura, Madrid, Taurus.

Van Roon, G. (1967): Neuordnung im Widerstand. Der Kreisauer Kreis innerhalb der deutschen Widerstandsbewegung, München, R. Oldenburg Verlag.

Wolers, F. (1927): Vier Reden über das Vaterland, Breslau, Ferdinand Hirt.

\begin{abstract}
The legitimacy of the aristocratic class which practically monopolised Germany's senior civil service between 1871 and 1918 took root in the ritual celebration of violence and death in war. Thanks to this ritual, the political language of the old regime acquired an abstract significance which gave meaning to the death of the individual. In Count Stauffenberg's biography, political concepts transcend the political sphere per se and death is presented as a "meaningful horizon" which is profoundly entrenched in the personality. The biographical crisis which afflicted Stauffenberg and other German noblemen in the wake of Germany's defeat in the first world war shows that political legitimacy was not at this time differentiated in purely political terms, but rather incorporated in an aristocratic class.
\end{abstract}

